Supporting Information

NCBSI/KI: A Reagent System for Iodination of Aromatics through in-situ Generation of I-Cl

Amey Palav, ${ }^{a, b}$ Balu Misal, ${ }^{a, b}$ Ganesh Chaturbhuj*a

${ }^{a}$ Department of Pharmaceutical Sciences and Technology, Institute of Chemical Technology,

Matunga, Mumbai, India 400019

${ }^{b}$ Loba Chemie Pvt. Ltd., Research, and Development Center, Tarapur, Thane, India 401506

*E-mail: gu.chaturbhuj@gmail.com

Table of Contents

\begin{tabular}{clc}
\hline Sr. No. & \multicolumn{1}{c}{ Description } & Pg. No. \\
\hline 1.0 & Copies of ${ }^{1} \mathrm{H}$ and ${ }^{13} \mathrm{C}$ NMR Spectra $\mathbf{2 a - 3 f}$ & S2-S16 \\
2.0 & Copies of mass spectra $\mathbf{2 c}, \mathbf{2 j}, \mathbf{3 c}$ and $\mathbf{3 f}$ & S17-S18 \\
3.0 & $\begin{array}{l}\text { Copies of }{ }^{1} \mathrm{H} \text { and }{ }^{13} \mathrm{C} \text { NMR of } N \text {-chloro- } N \text {-(phenylsulfonyl)benzene } \\
\text { sulfonamide }\end{array}$ & S-19 \\
\hline
\end{tabular}




\subsection{Copies of ${ }^{1} \mathrm{H}$ and ${ }^{13} \mathrm{C}$ NMR Spectra}

1. 2-Iodo-4-nitroaniline, 2 a

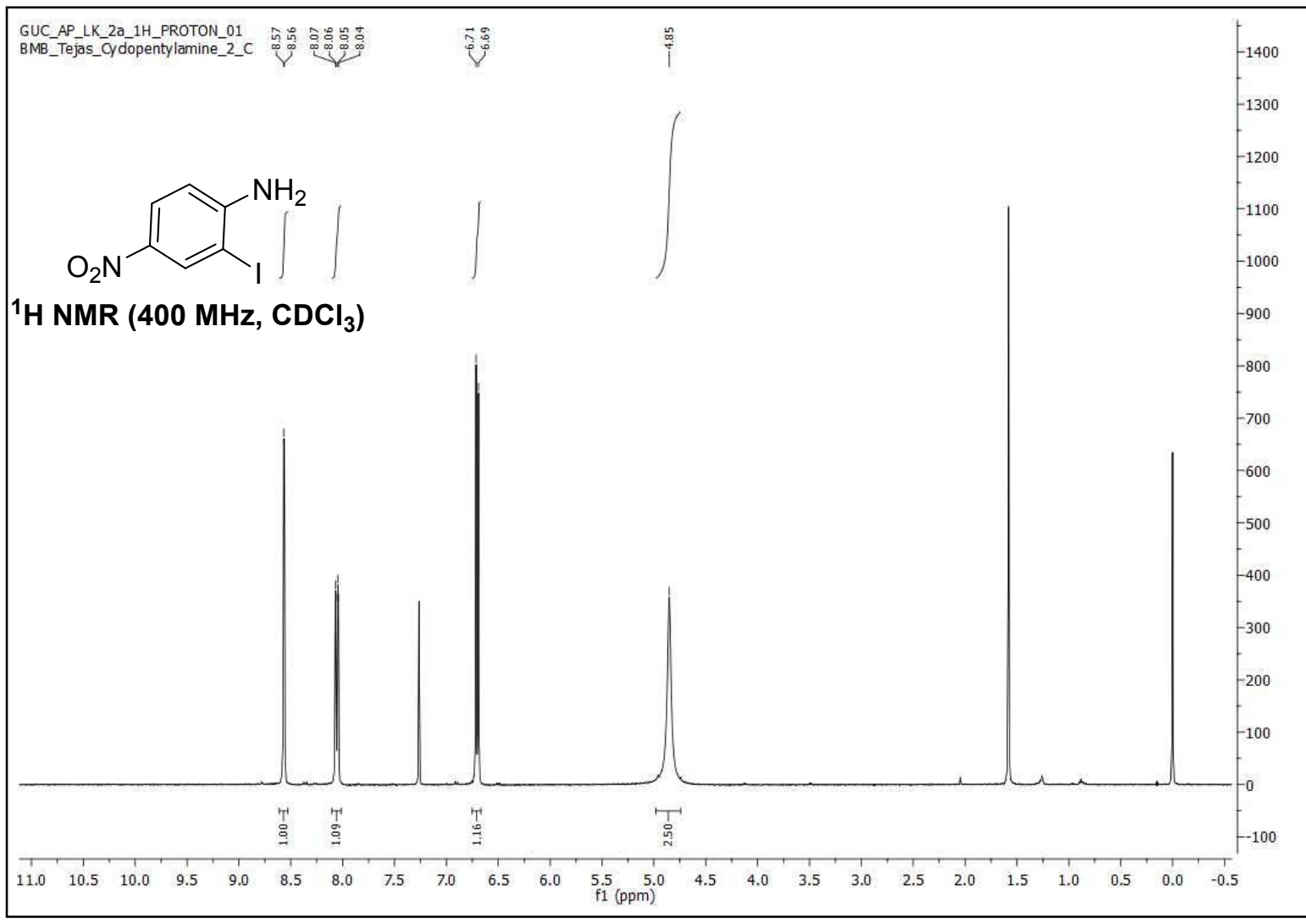

2. 4-Iodo-2-nitroaniline, $2 b$

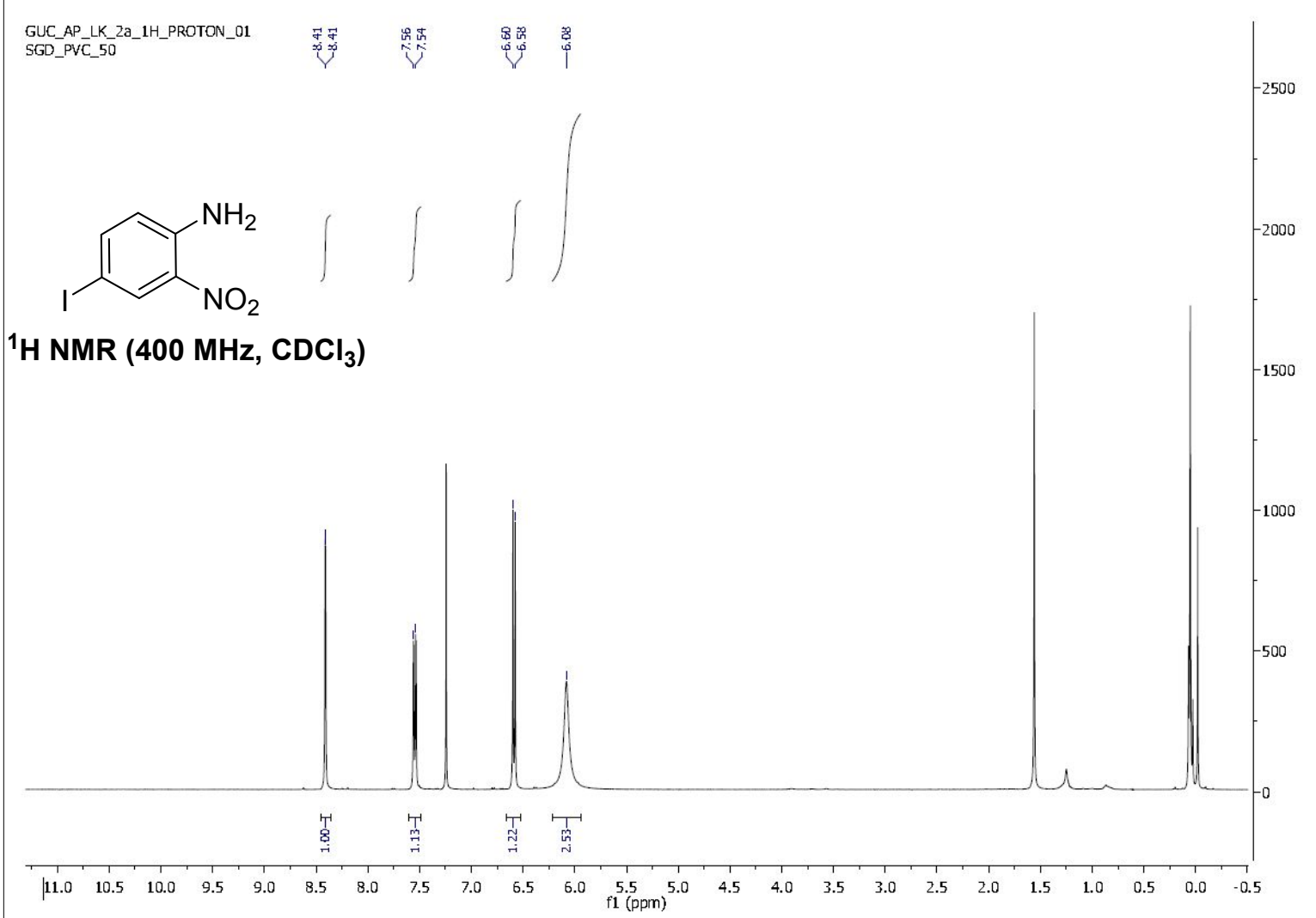


3. 2-Chloro-6-iodo-4-nitroaniline, 2c

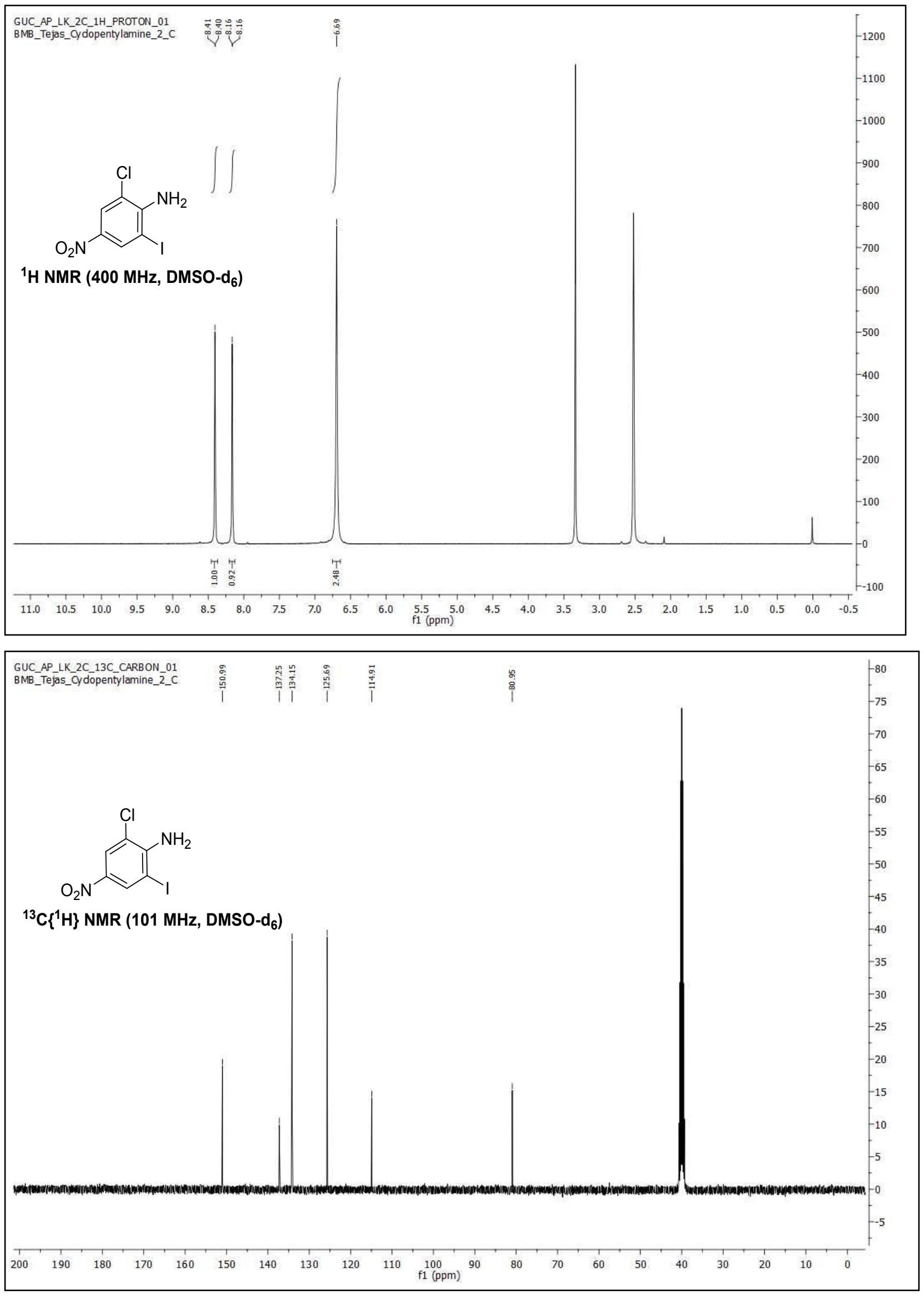


4. 4-Chloro-6-iodo-2-nitroaniline, 2d:

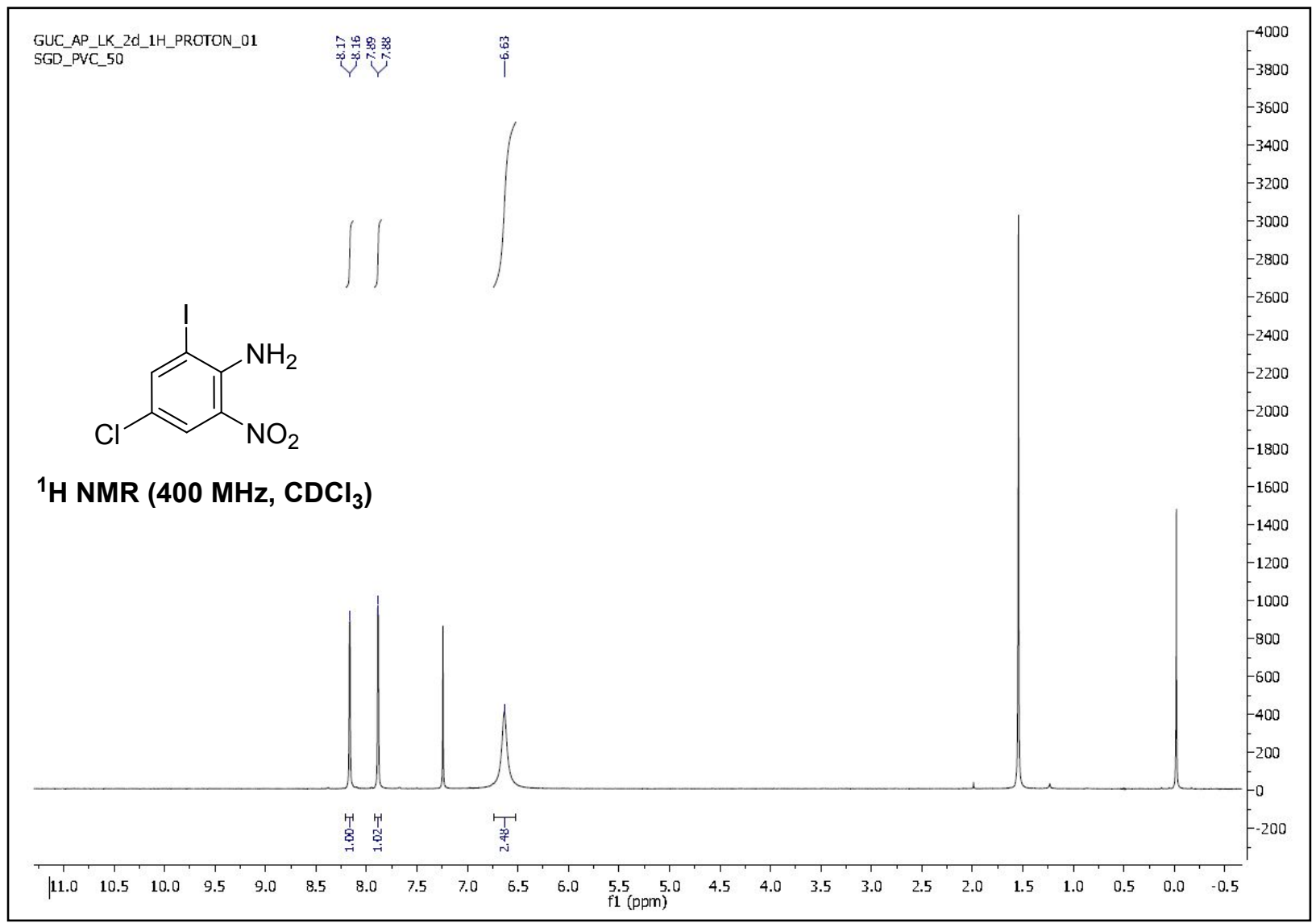

5. 4-Chloro-2-iodoaniline, 2e:

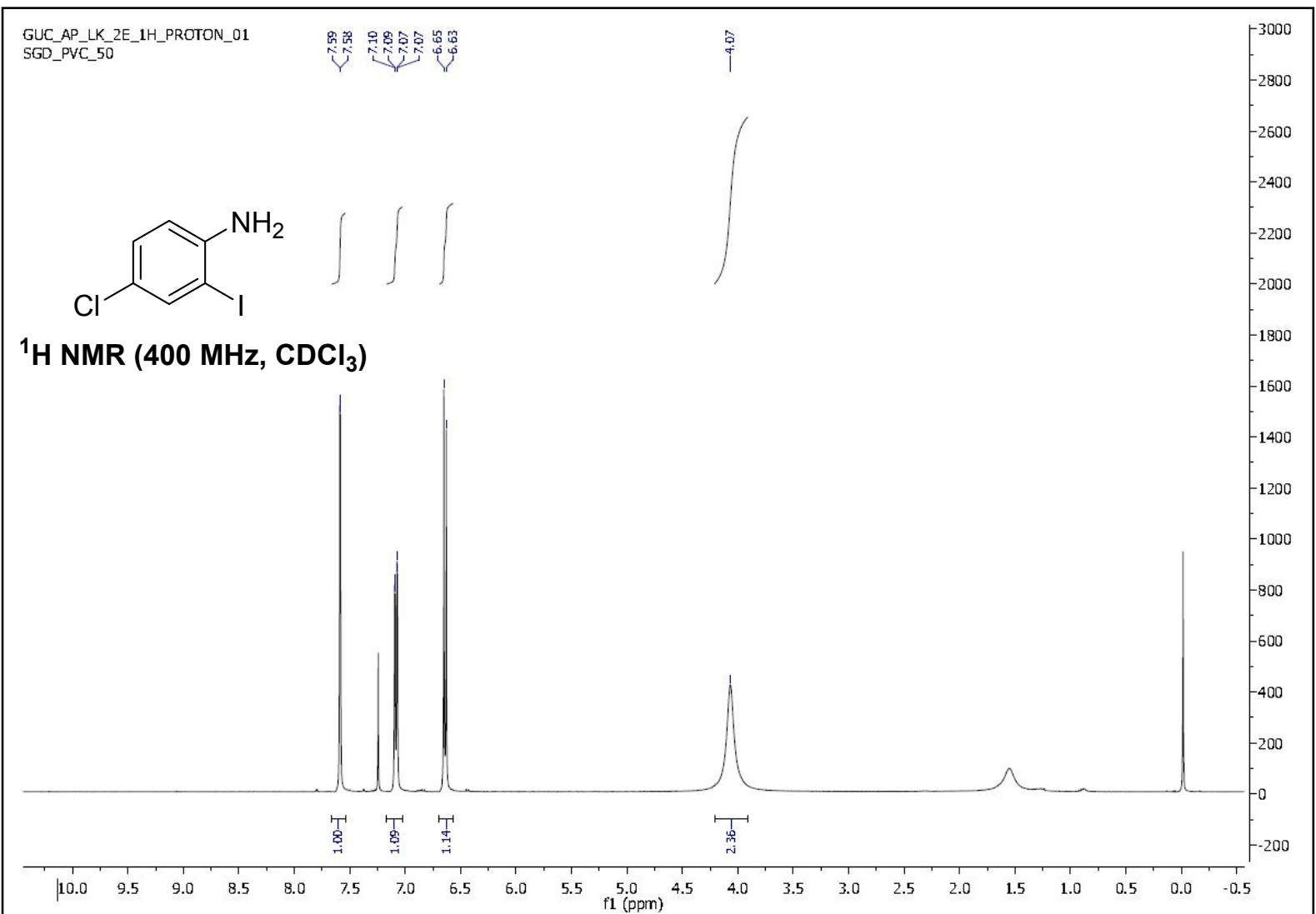


6. 2-Chloro-4-iodoaniline, $2 \mathrm{f}$ :

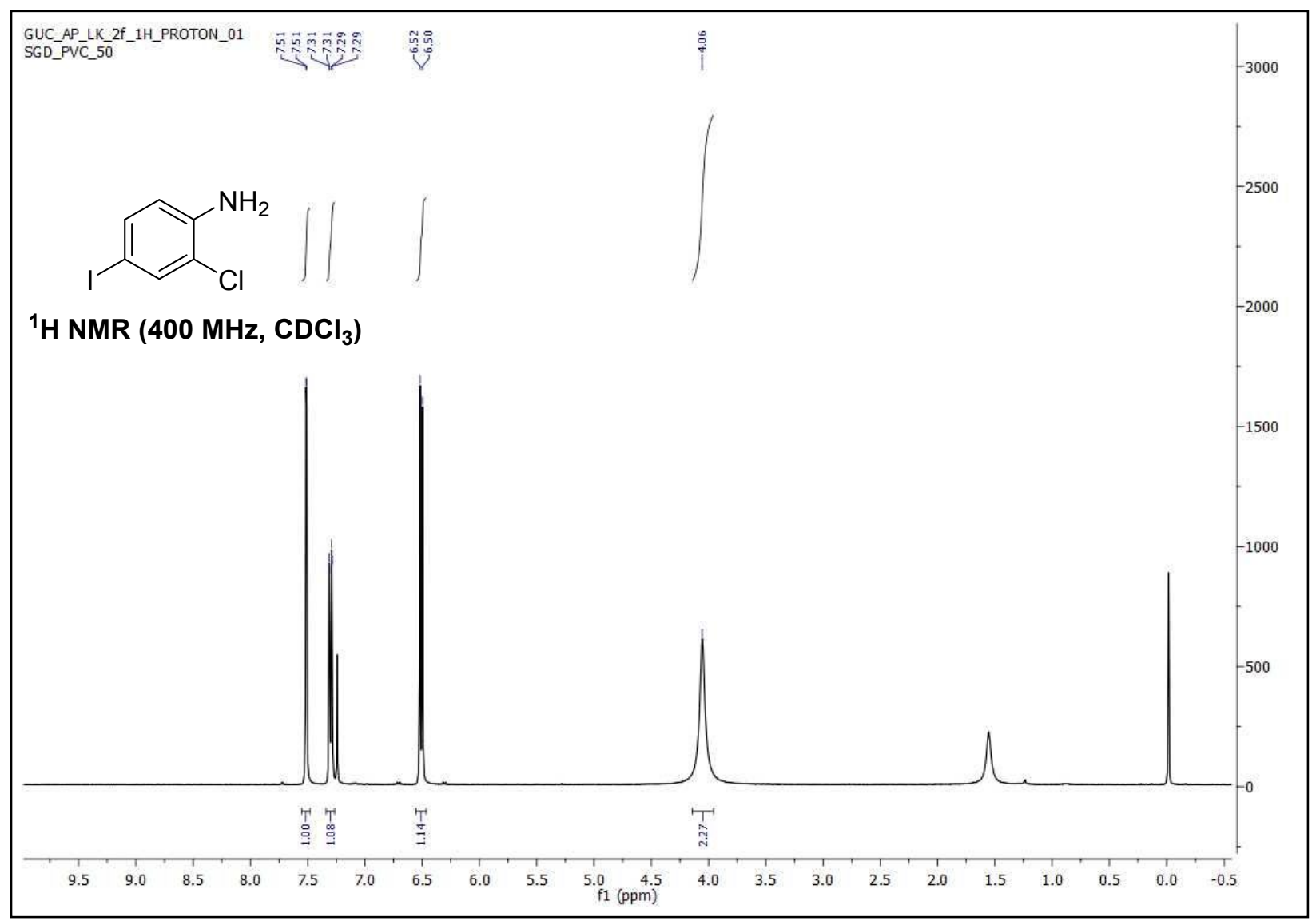

7. 4-iodo-2-methylaniline, 2g:

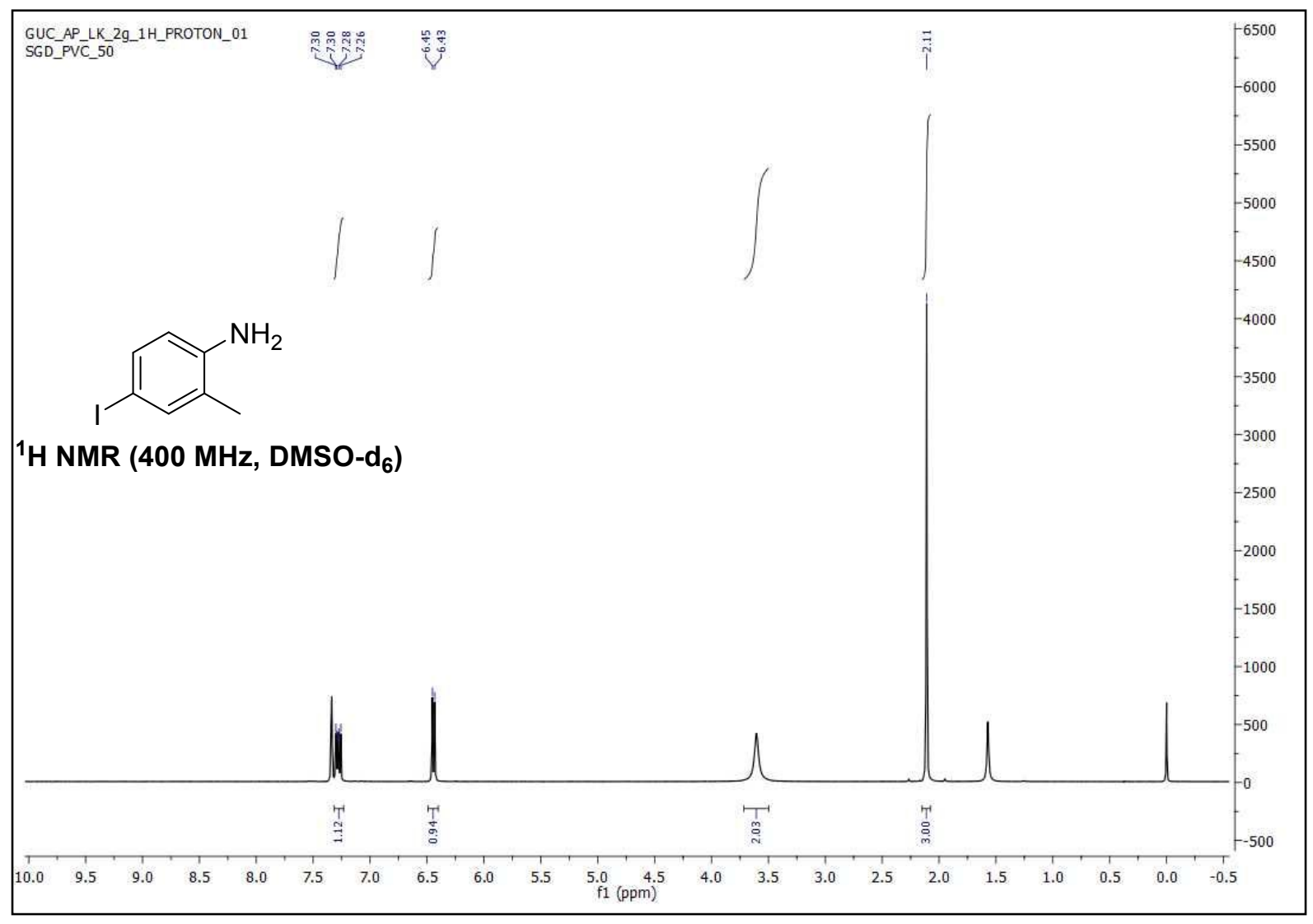

S5 
8. Methyl 2-amino-5-iodobenzoate, $2 \mathrm{~h}$ :

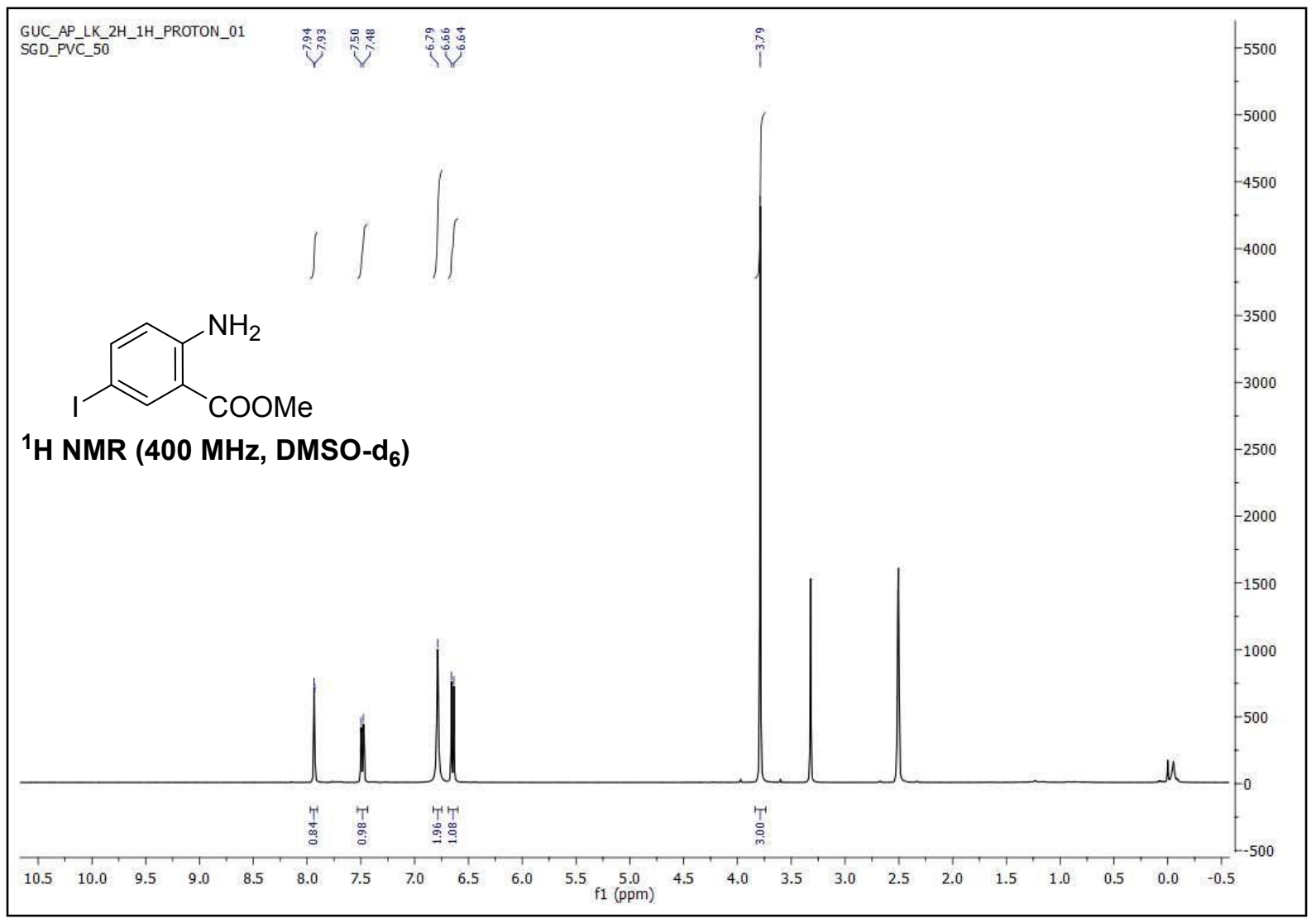

9. 4-Iodoacetanilide, 2i:

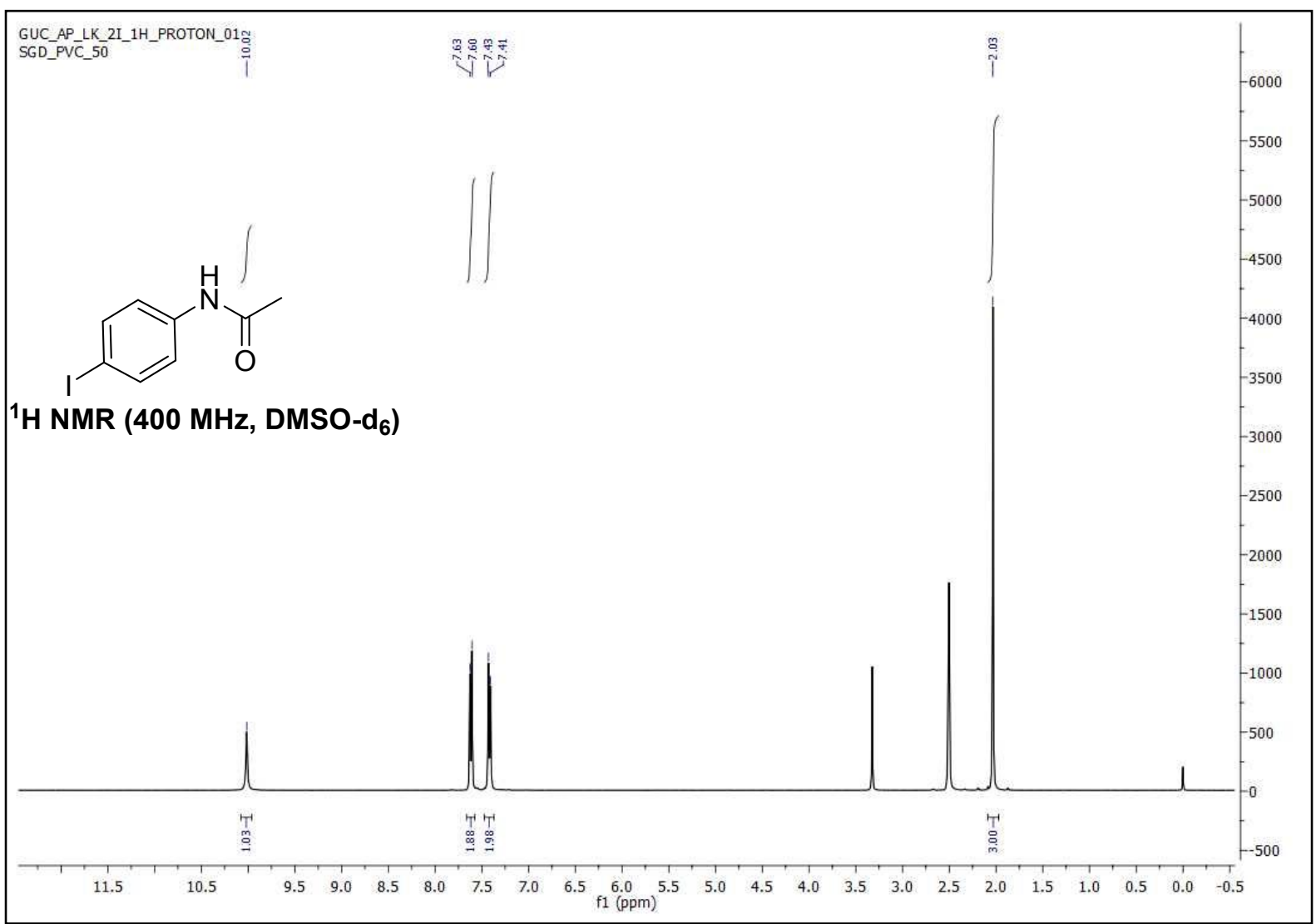


10. 1-Acetamido-4-iodonaphthalene, $2 \mathrm{j}$ :
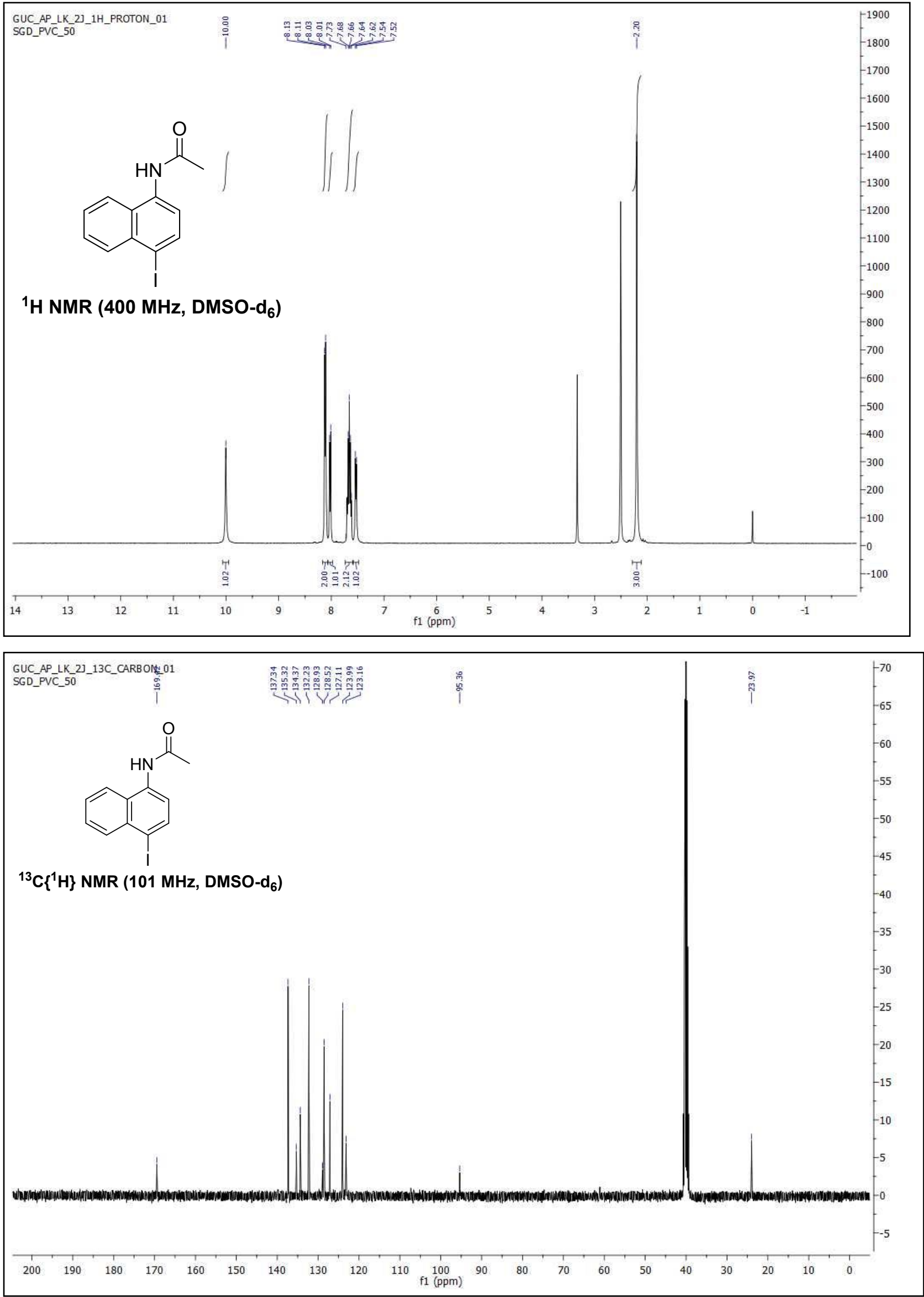
11. 2-Amino-5-iodopyridine, 2k:

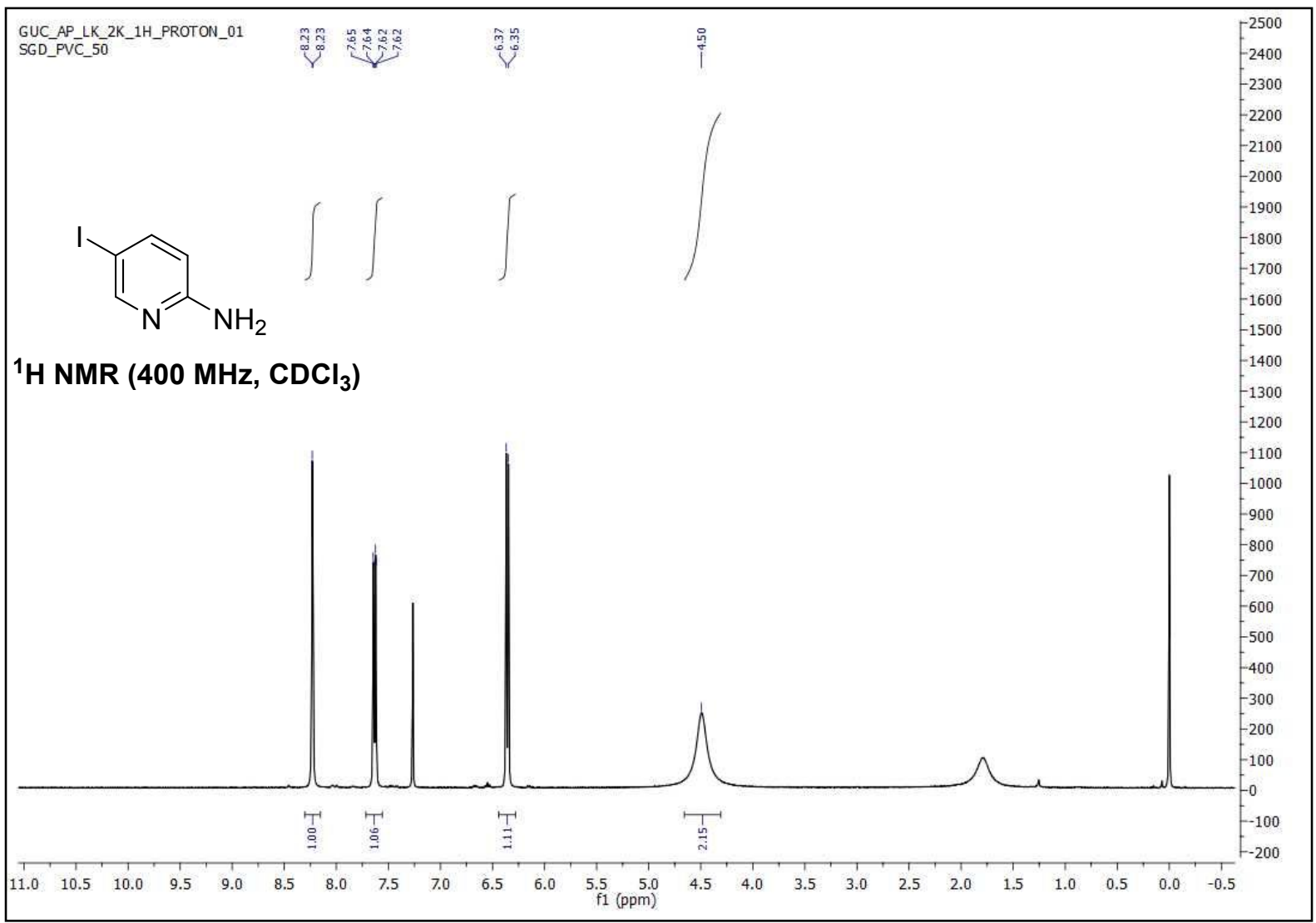

12. 4-iodo-2-nitrophenol, 21:

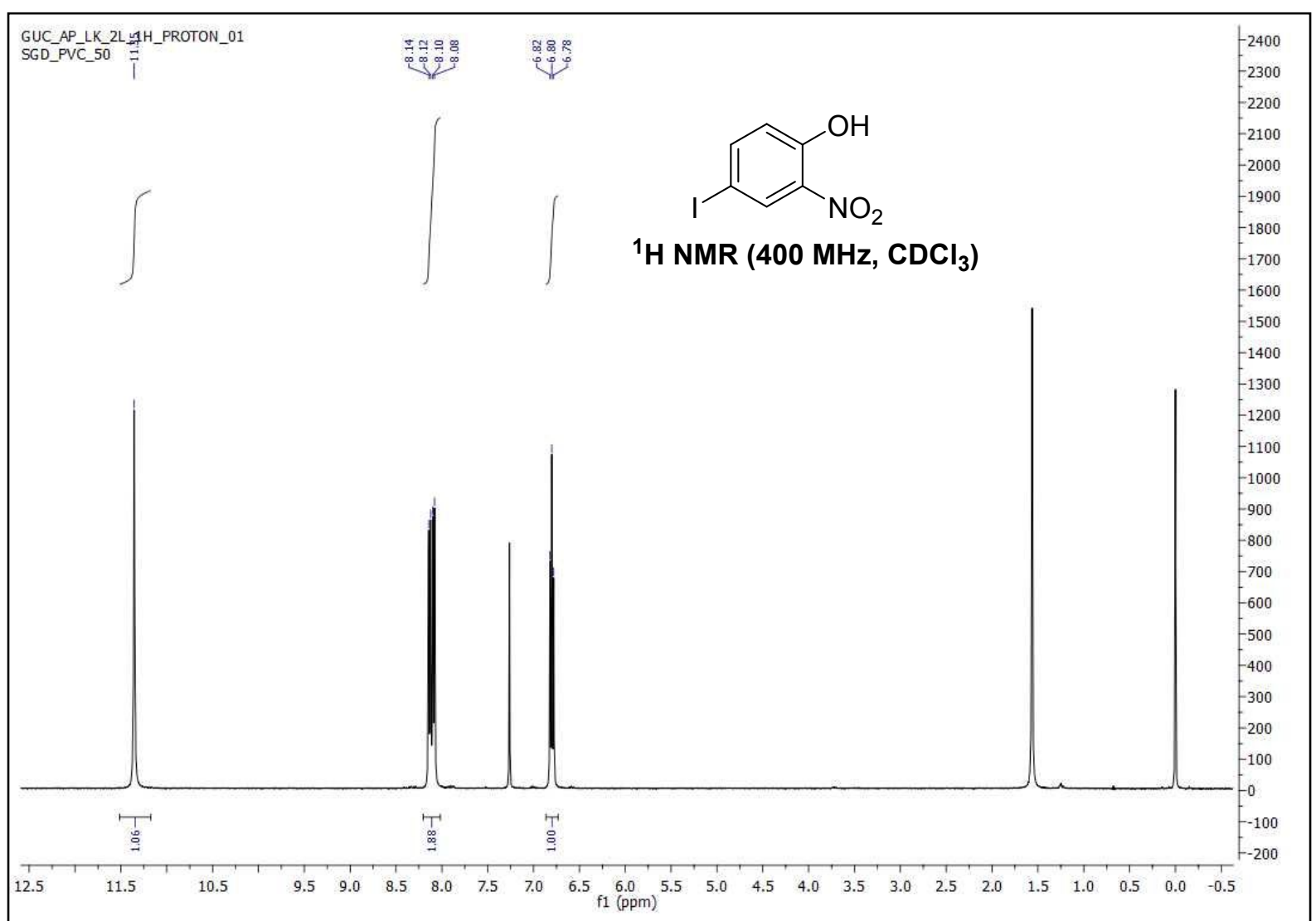


13. 2,4-Dichloro-6-iodophenol, $2 \mathrm{~m}$ :

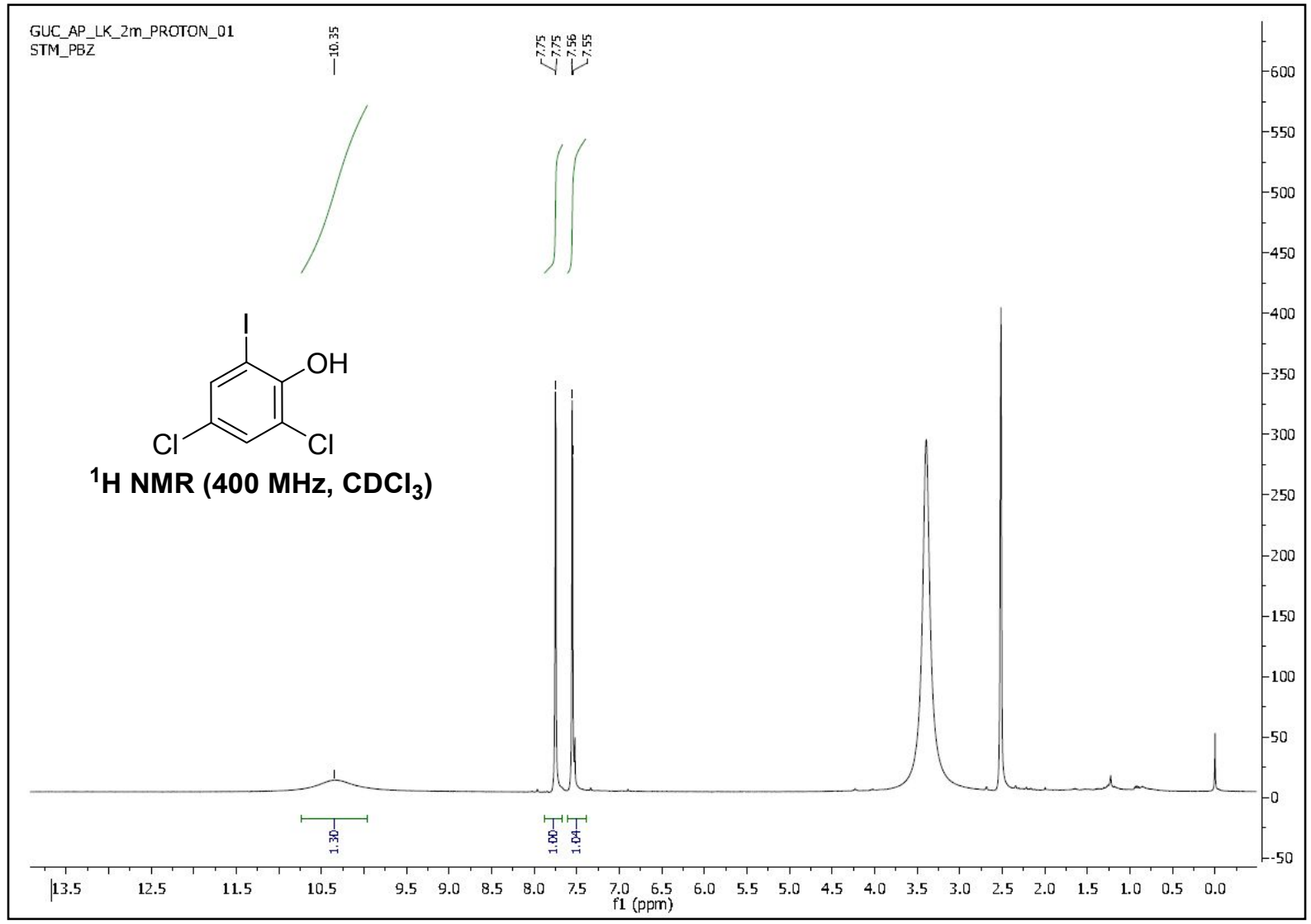

14. 4-Hydroxy-3, 5-diiodobenzaldehyde, 2n:

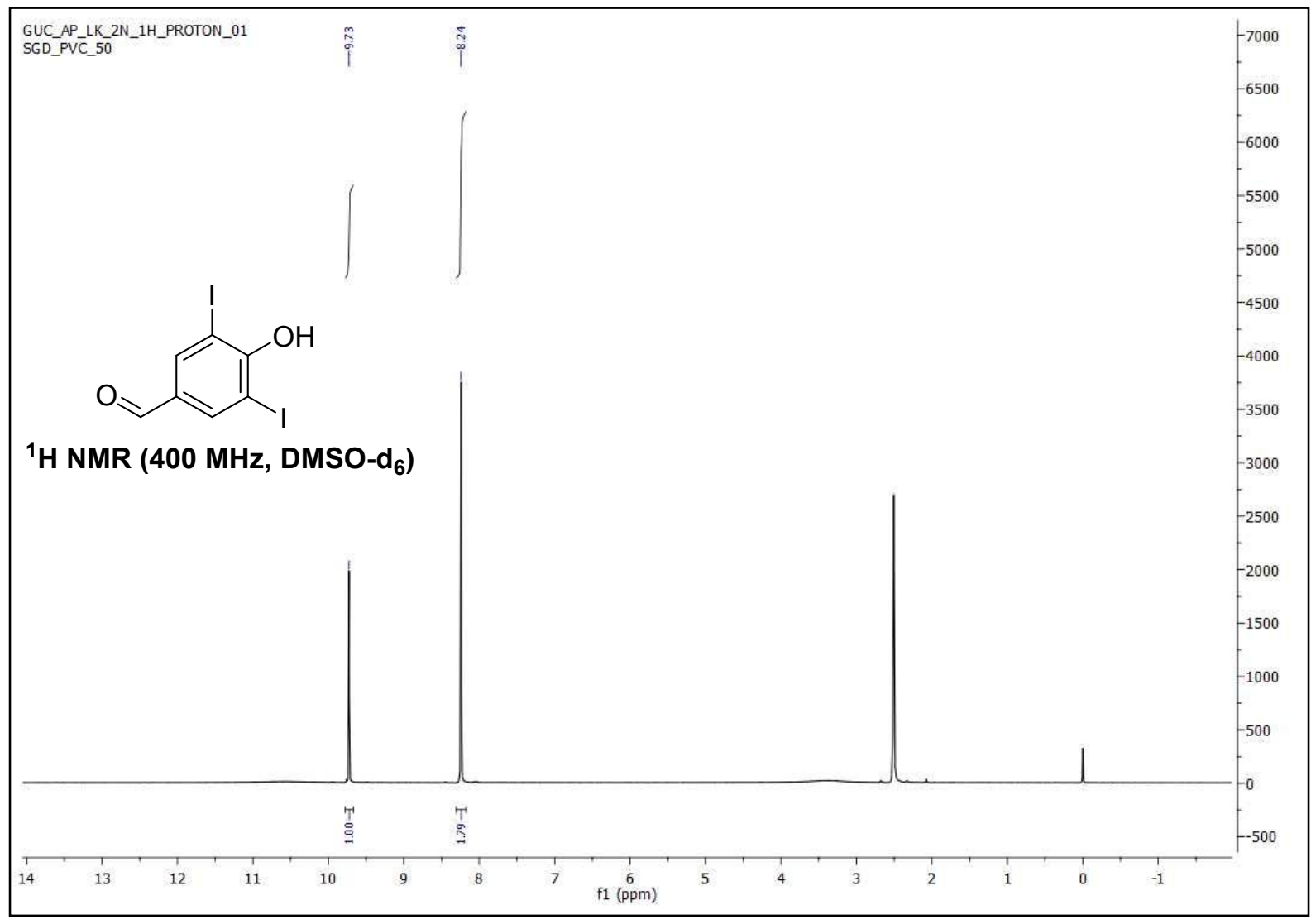


15. 2-Hydroxy-5-iodobenzoic acid, 2o:

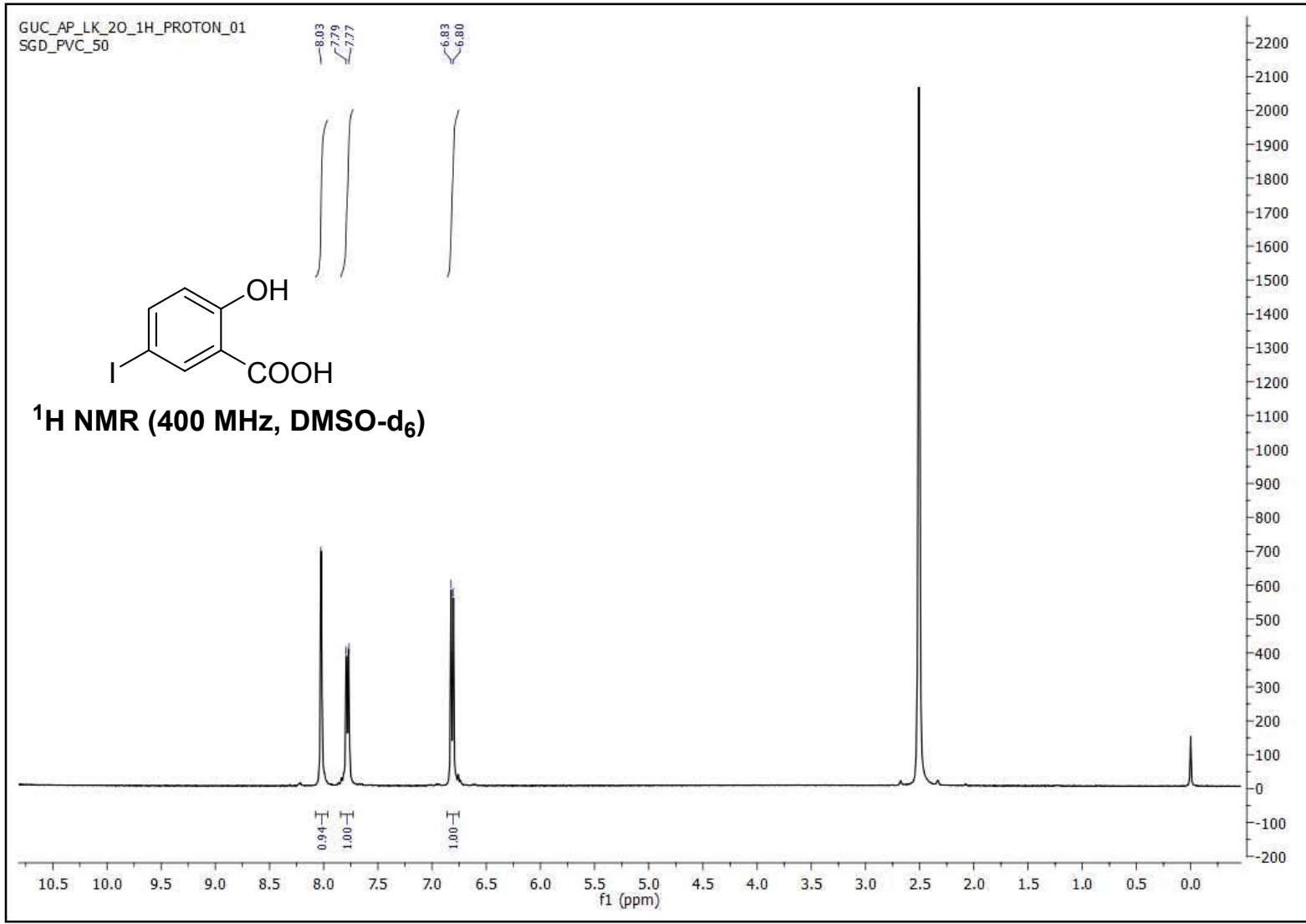

16. 4-Iodoanisole, $2 \mathrm{p}$ :

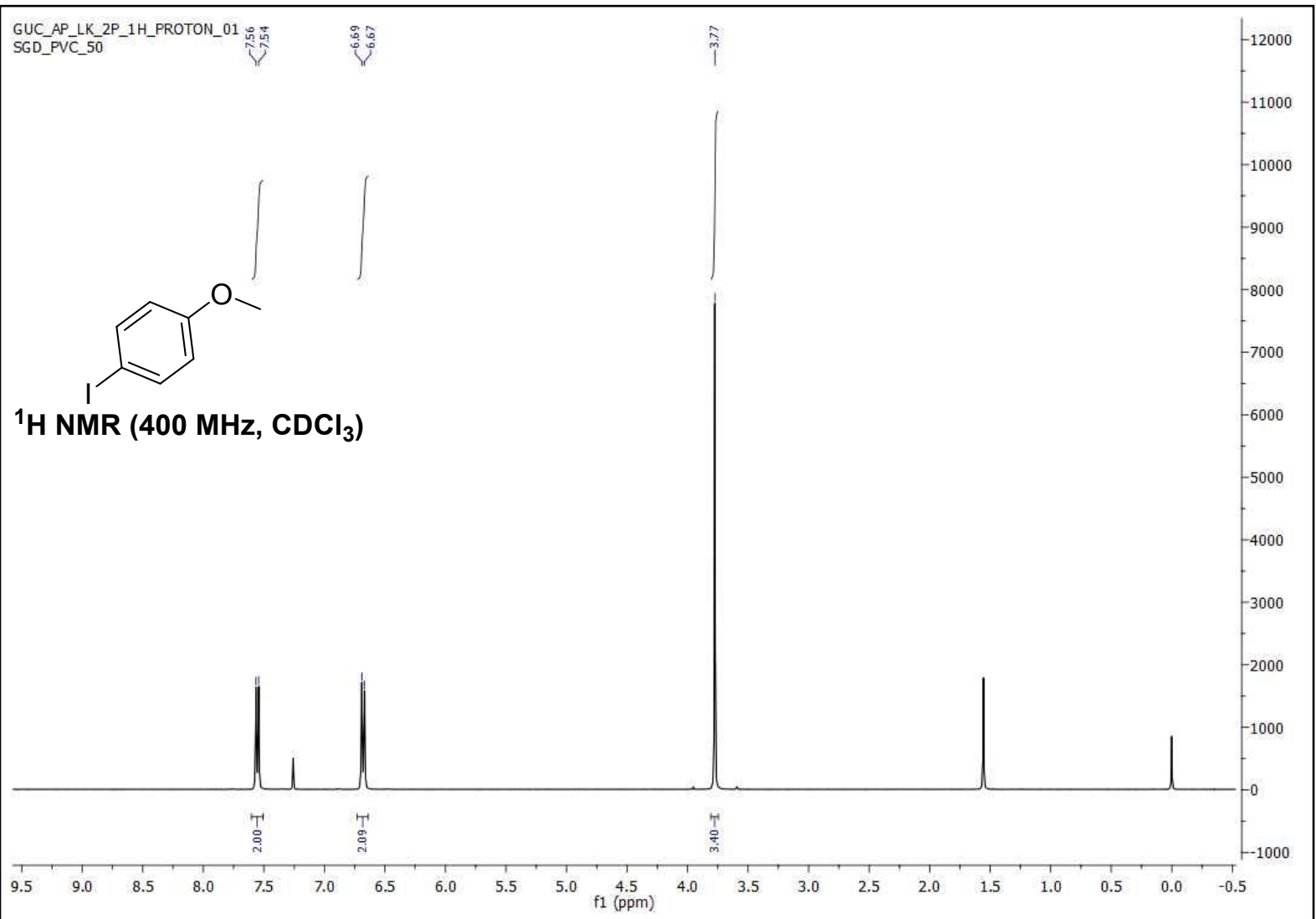


17. 1-iodo-4-methoxy-3-methylbenzene 2q:

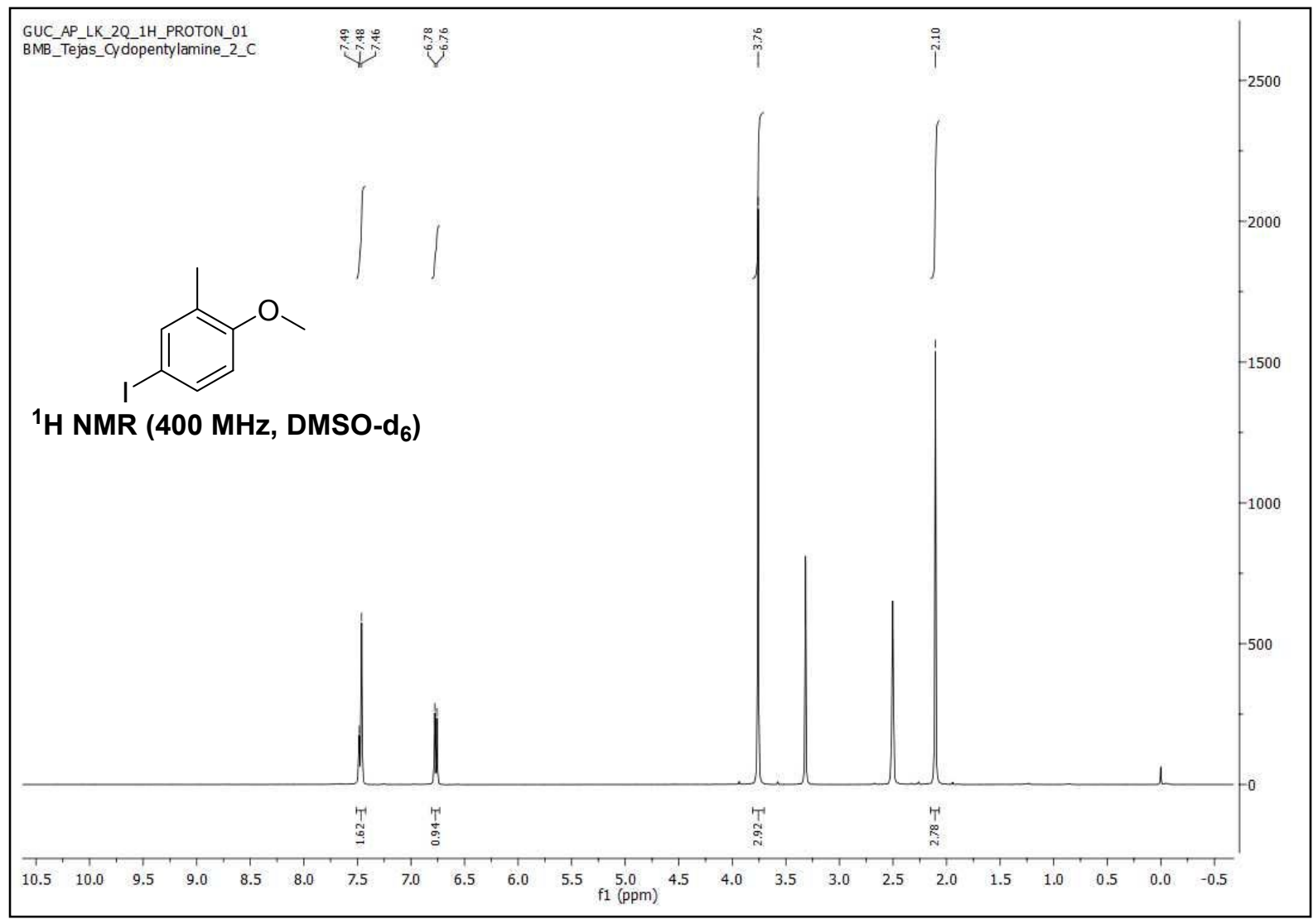

18. 1-Iodo-2-methoxynaphthalene, 2r:

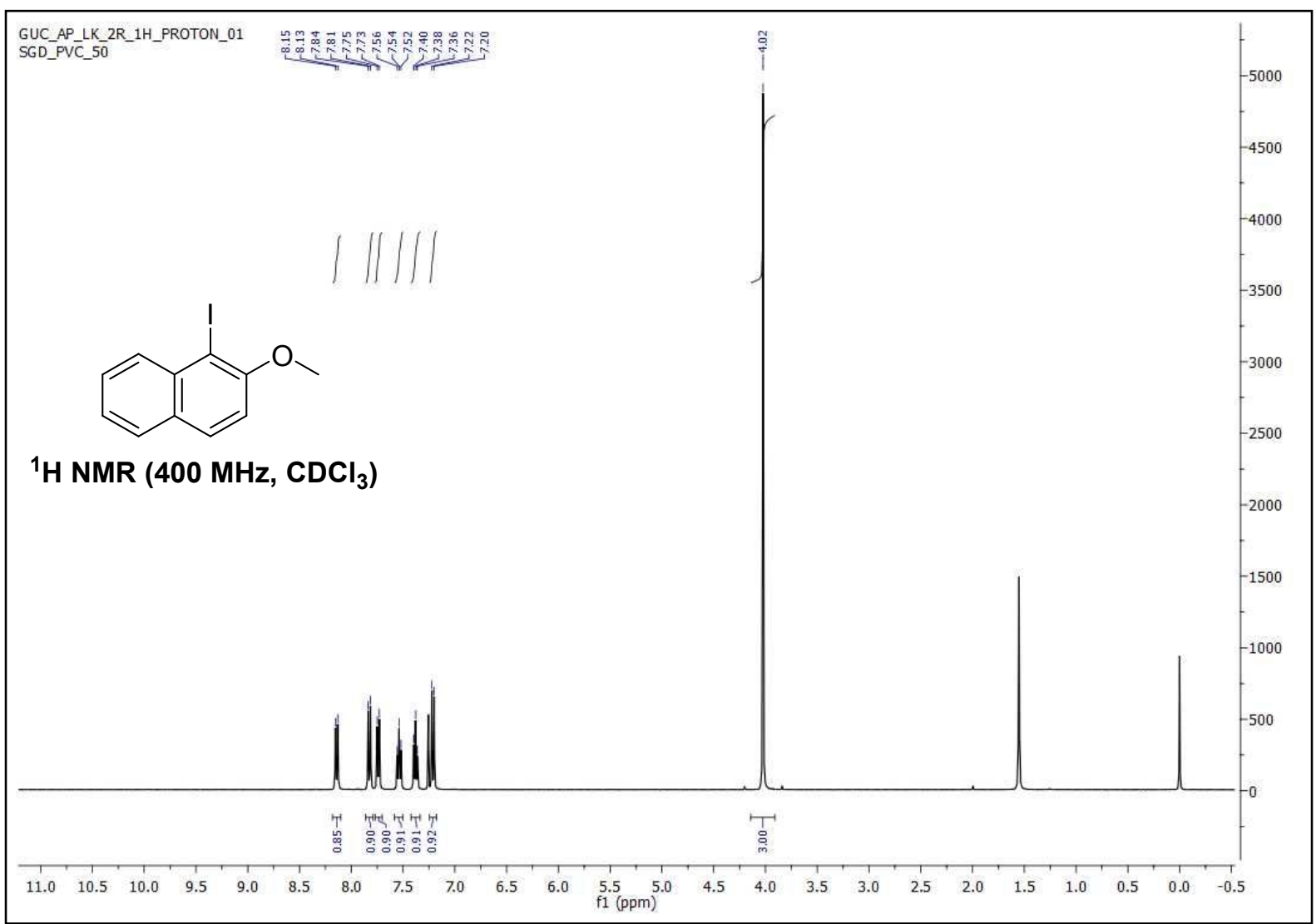


19. 2-Iodomesitylene, 2s:

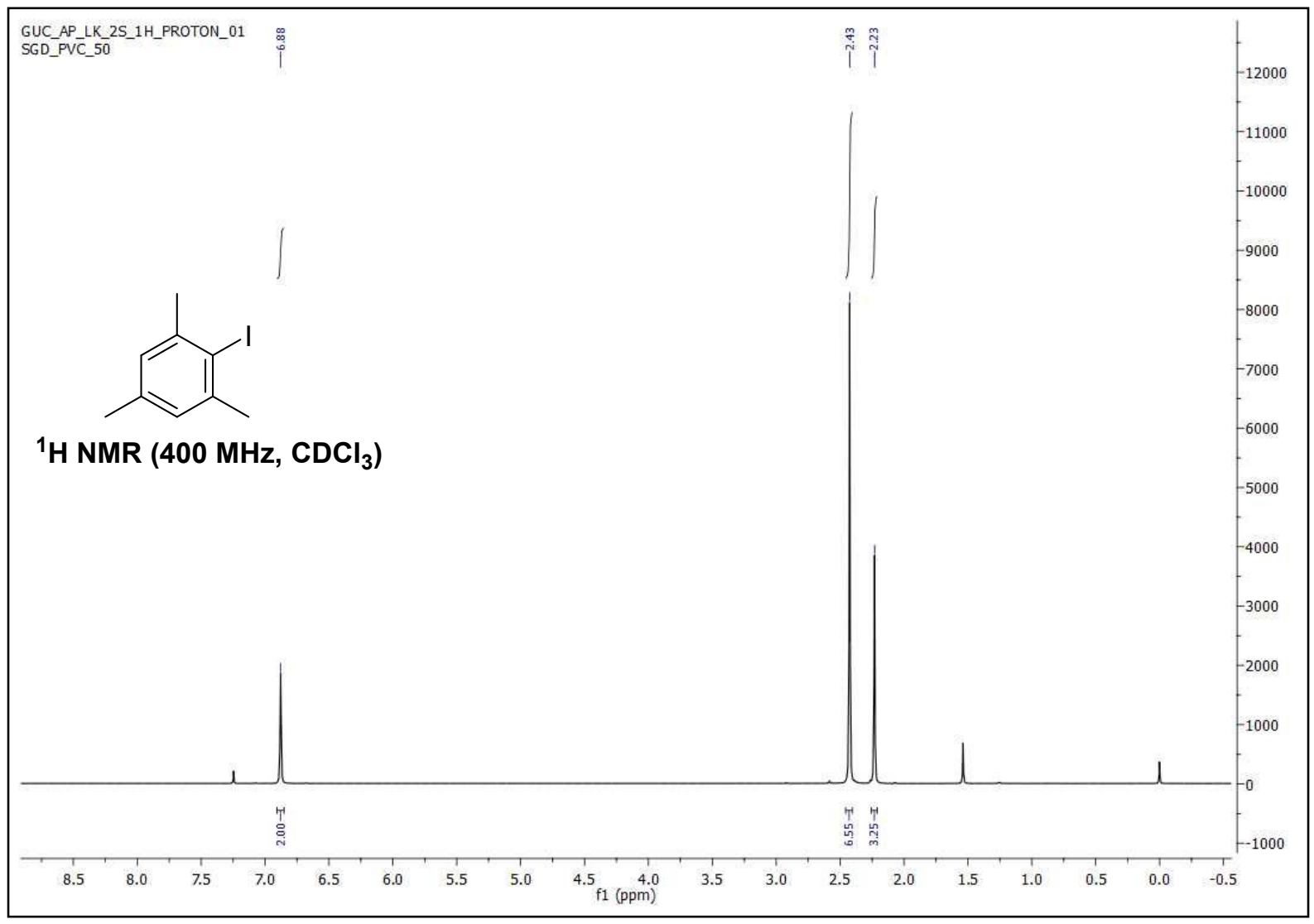

20. Iodobenzene, 2t:

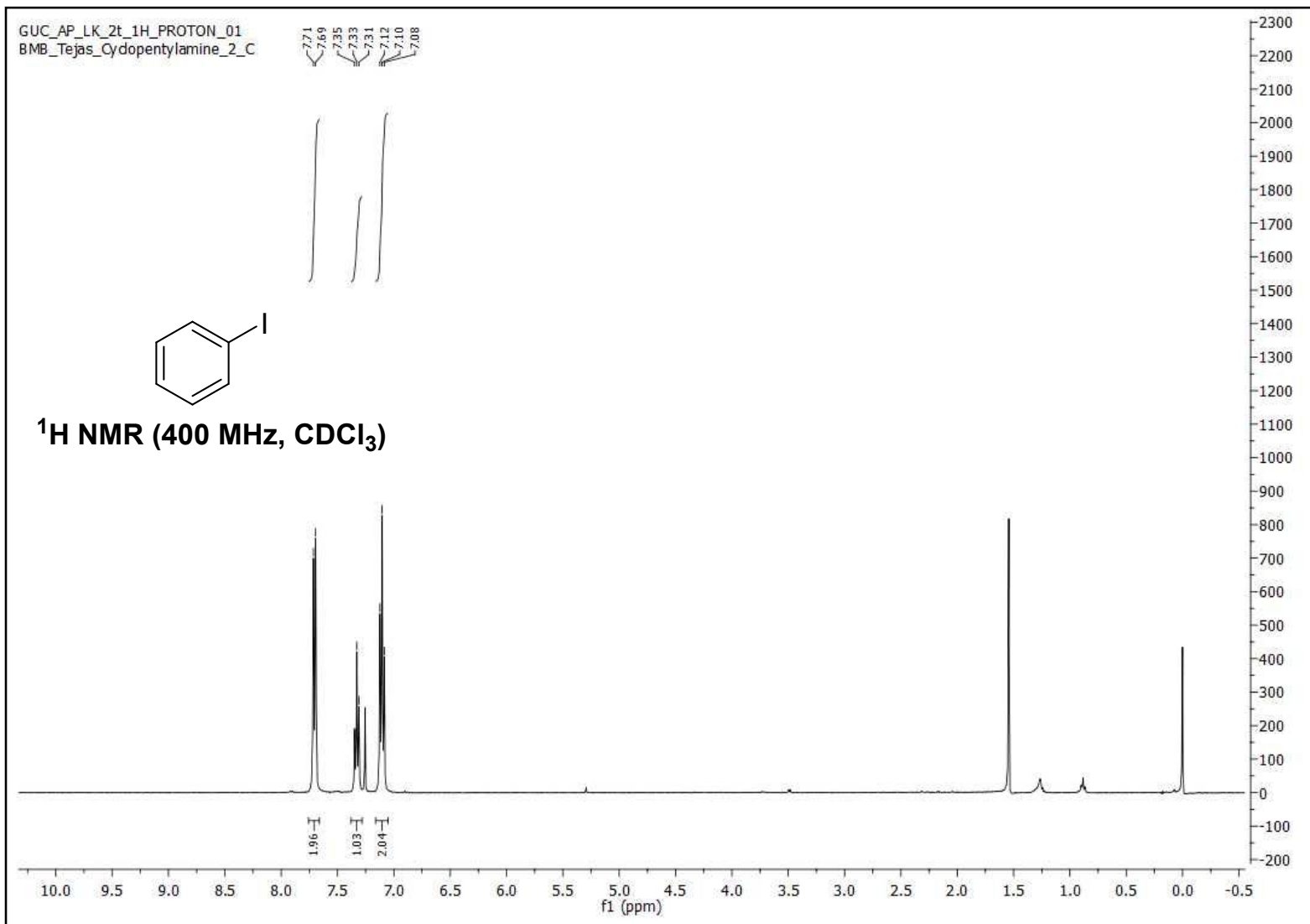


21. 2,6-Diiodo-4-nitroaniline, 3a:

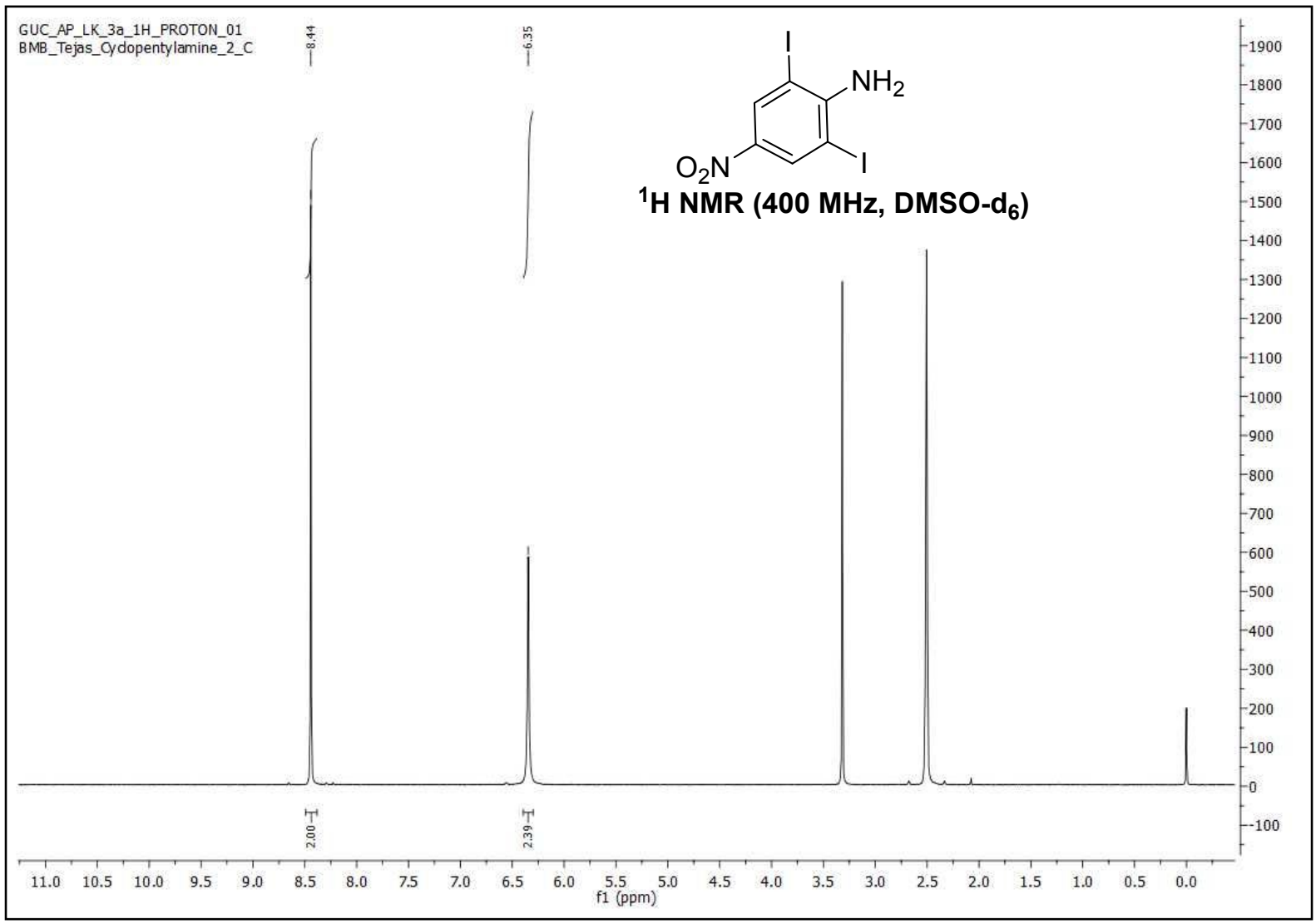

22. 4,6-Diiodo-2-nitroaniline, 3b:

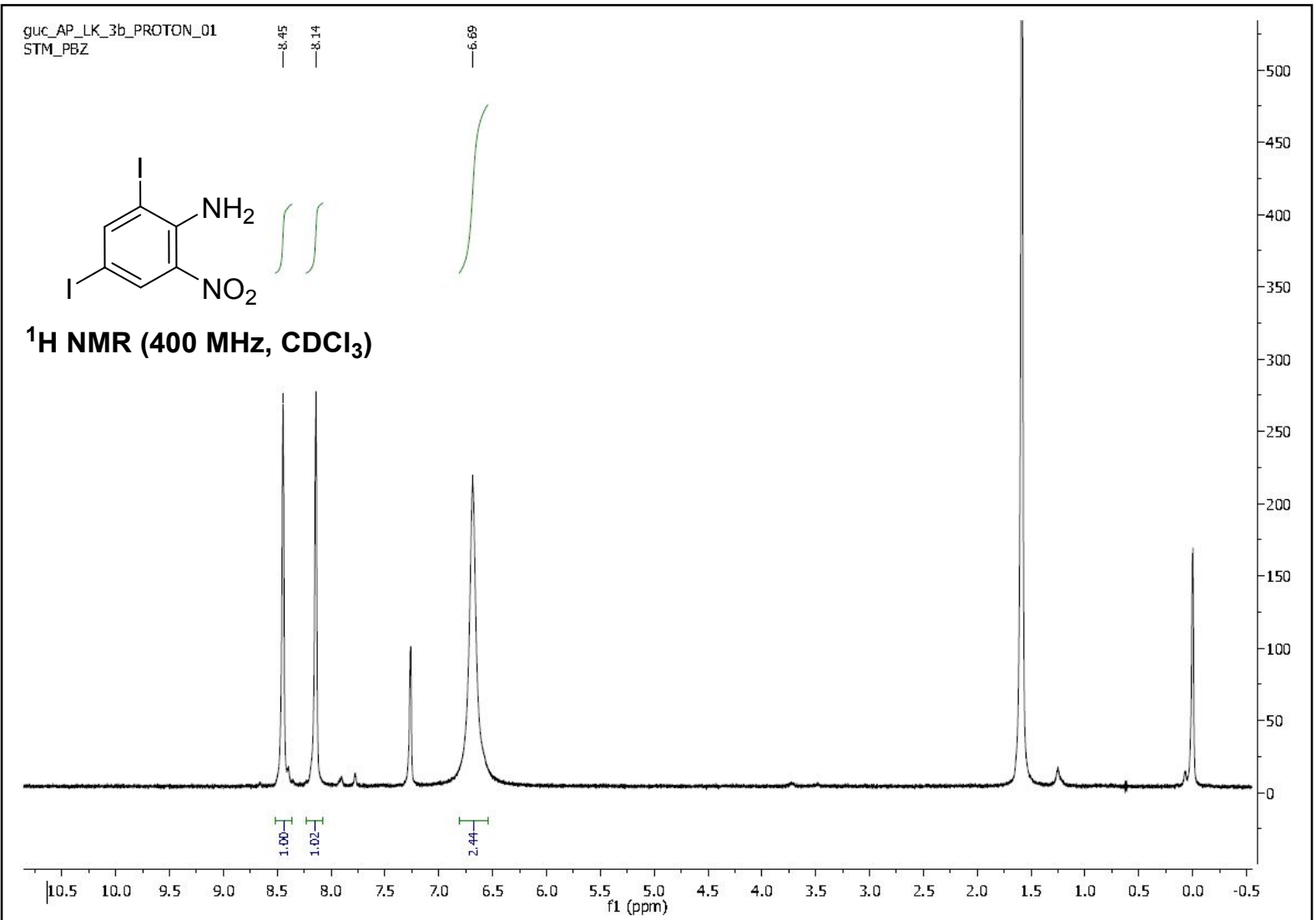


23. Methyl 2-amino-3,5-diiodobenzoate, 3c:
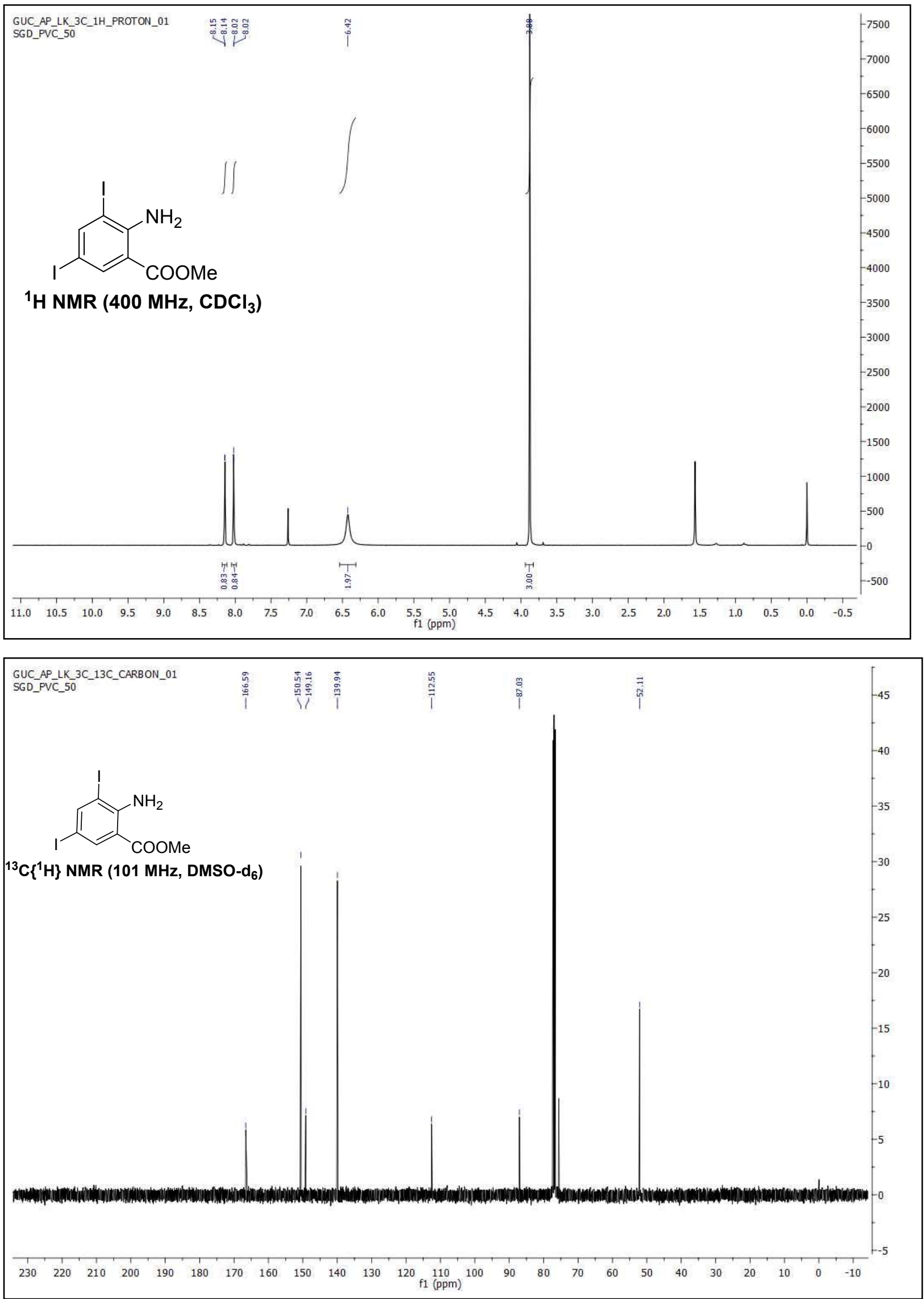
24. 4-Hydroxy-3,5-diiodobenzoic acid, 3d:

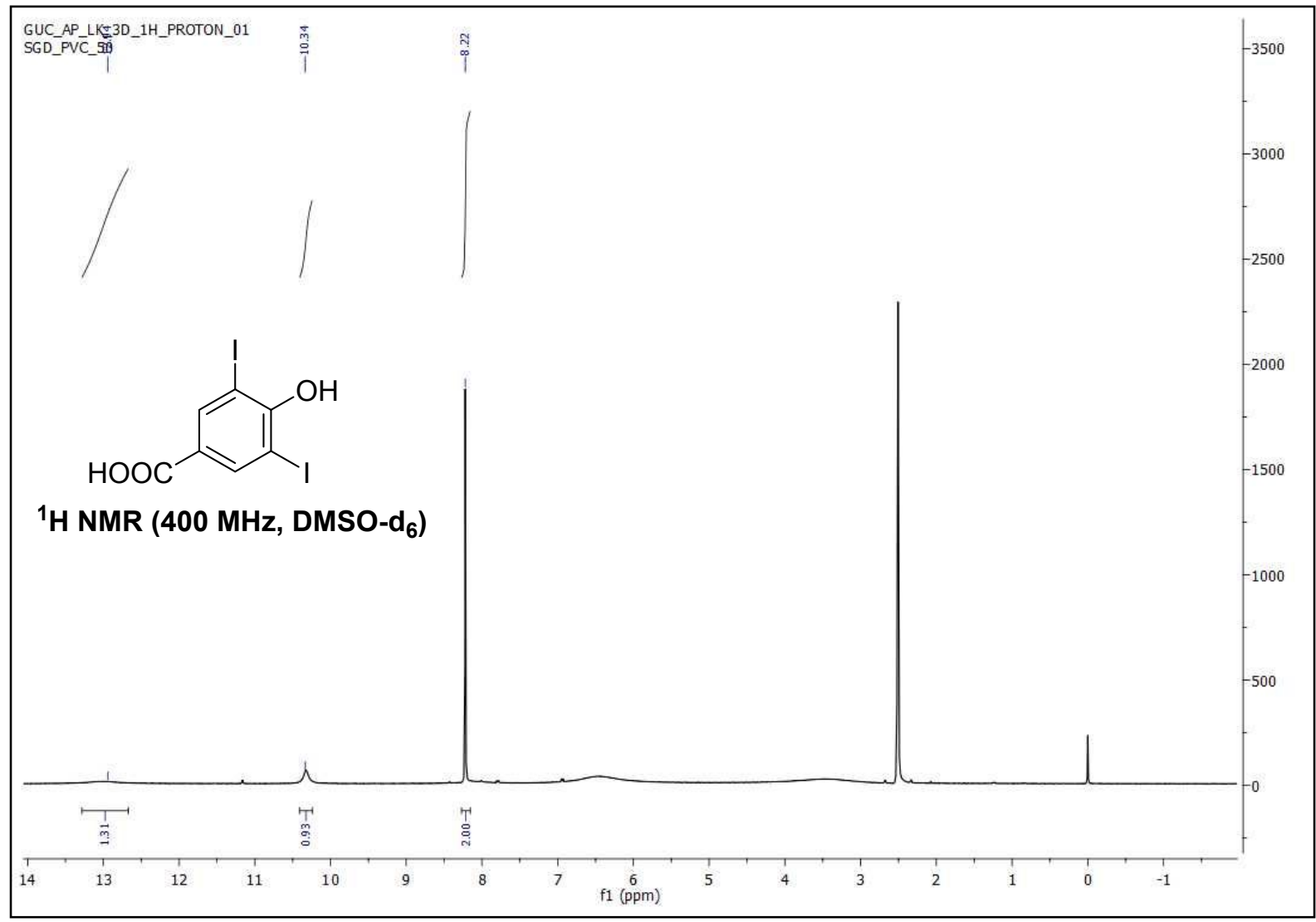

25. 2-Hydroxy-3,5-diiodobenzoic acid, 3e:

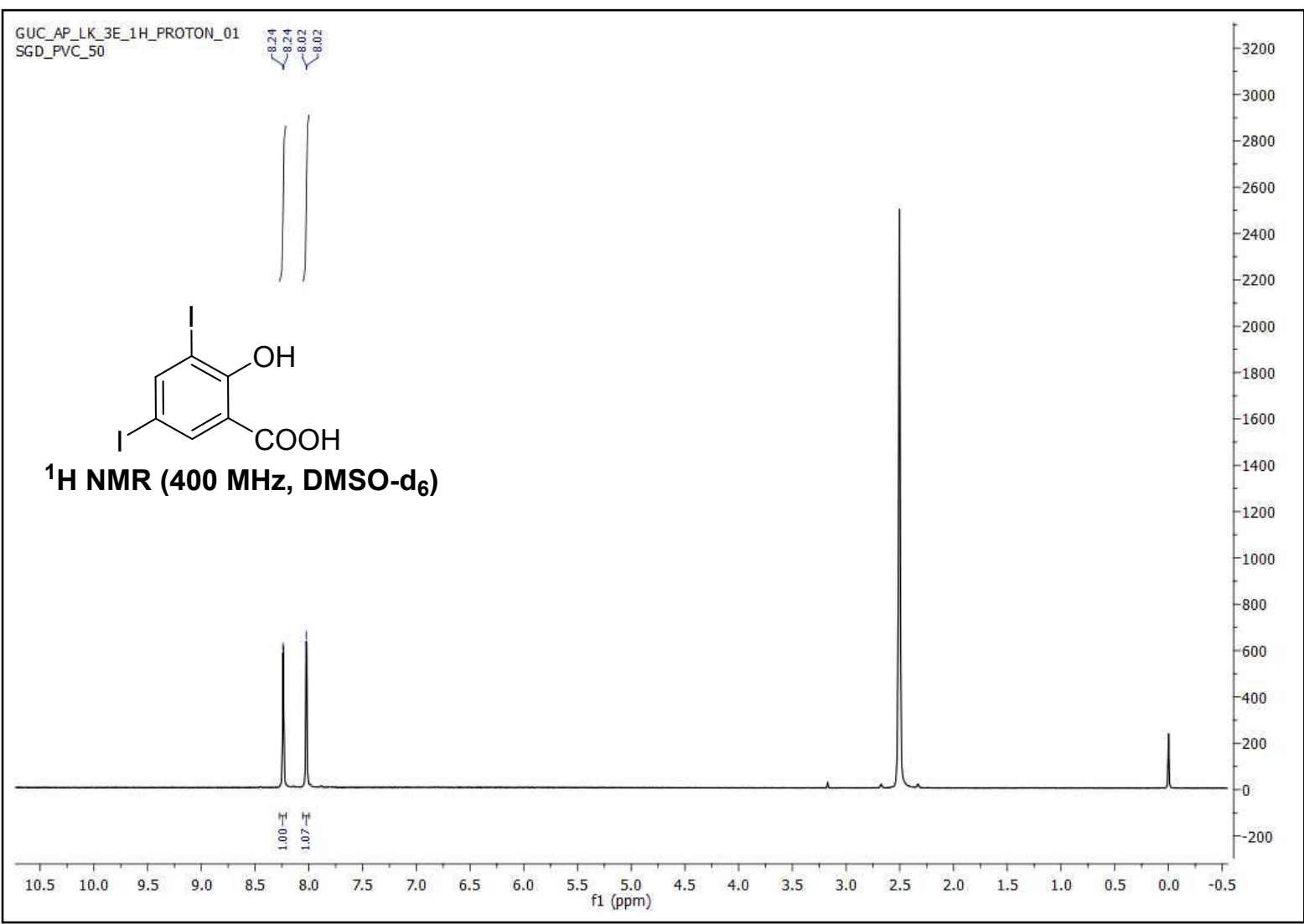


26. 4-Hydroxy-3,5-diiodophenylacetic acid, 3f:
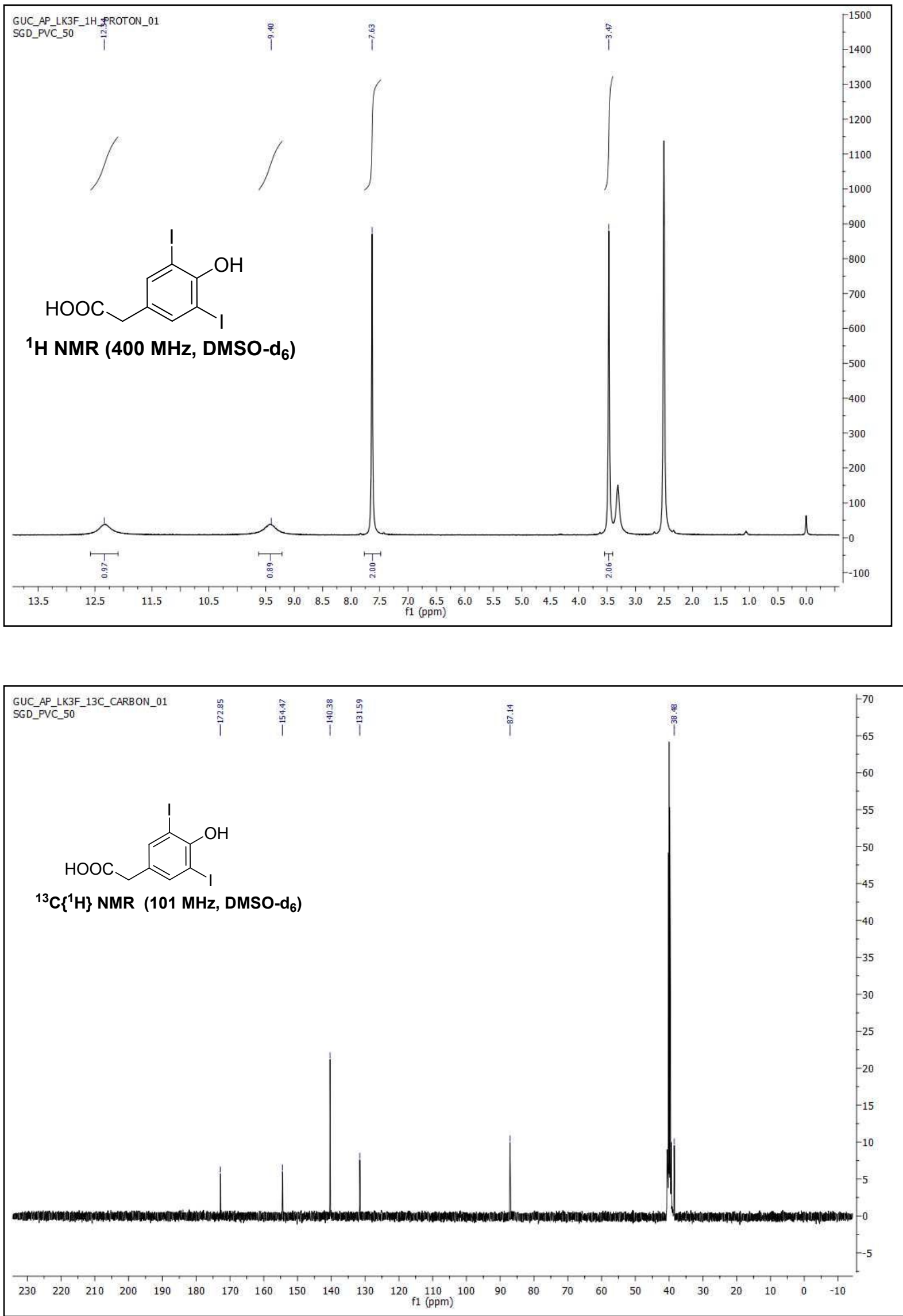


\subsection{Mass Spectra:}

\section{2-Chloro-6-iodo-4-nitroaniline, 2c}

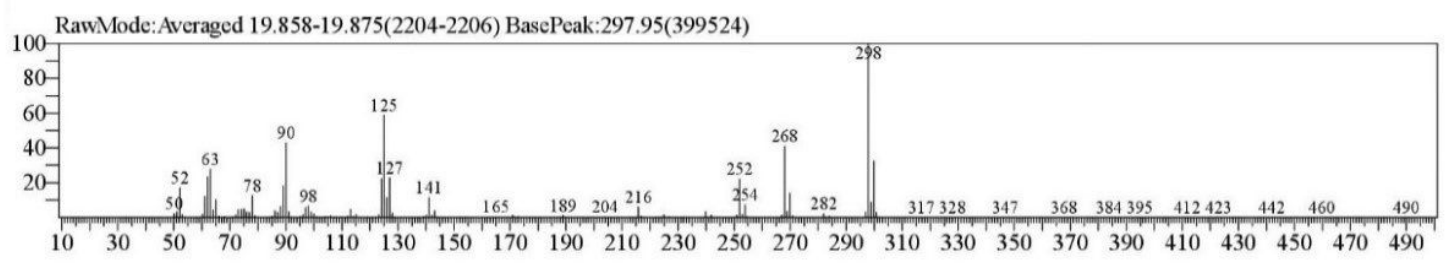

\section{1-Acetamido-4-iodonaphthalene, $2 \mathrm{j}$ :}

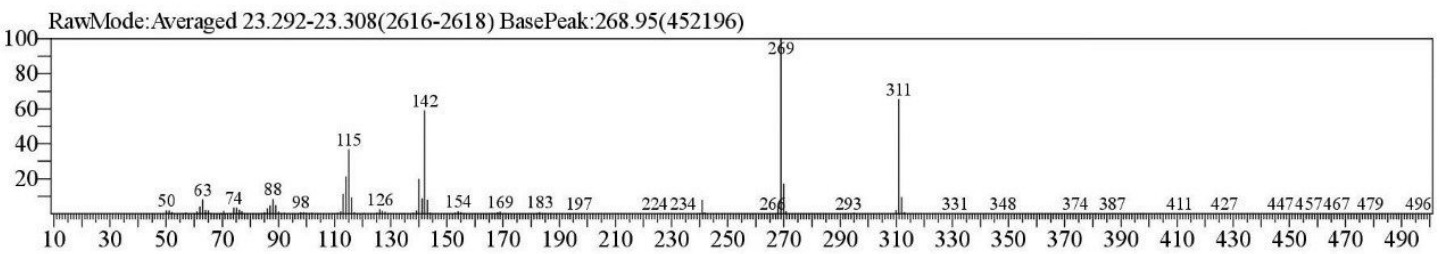

\section{Methyl 2-amino-3,5-diiodobenzoate, 3c:}

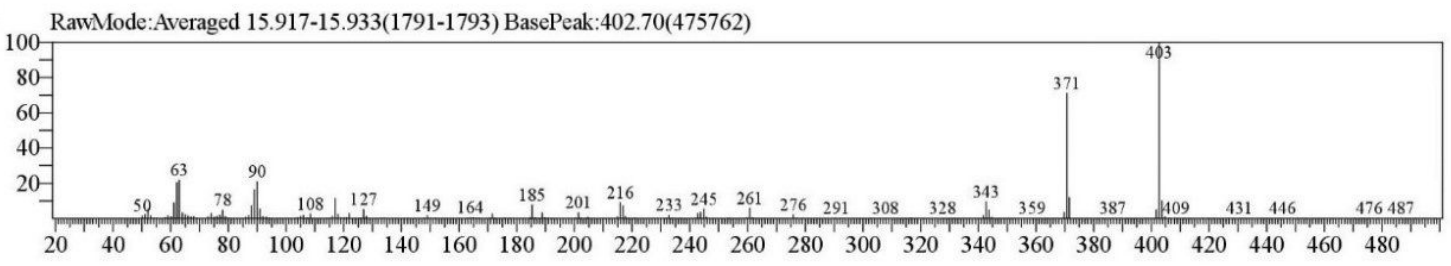


4-Hydroxy-3,5-diiodophenylacetic acid, 3f:

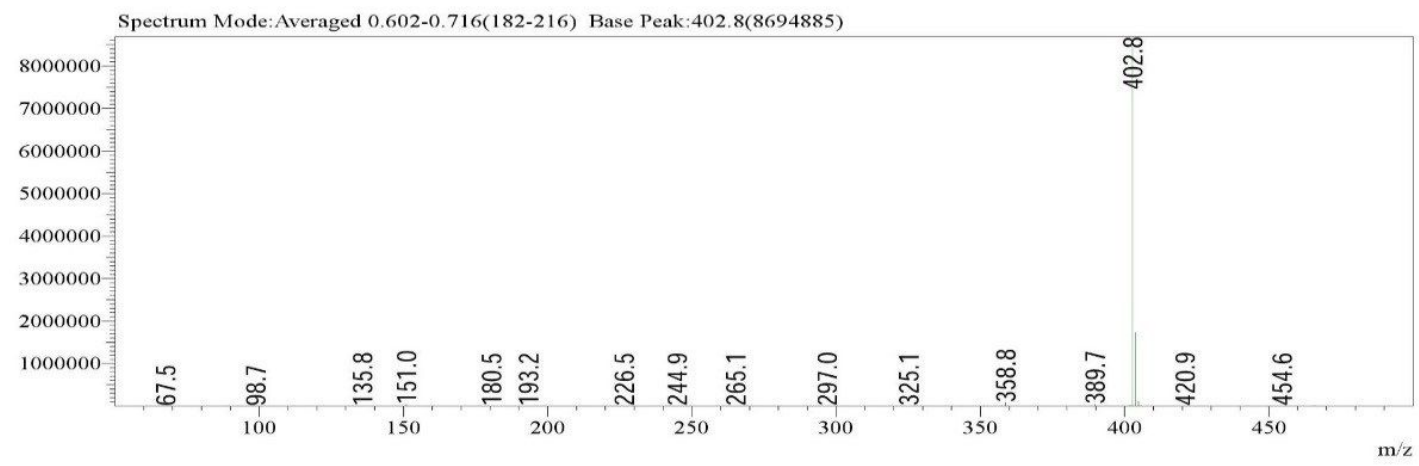




\section{$3.0{ }^{1} \mathrm{H}$ and ${ }^{13} \mathrm{C}$ NMR of recovered NCBSI}
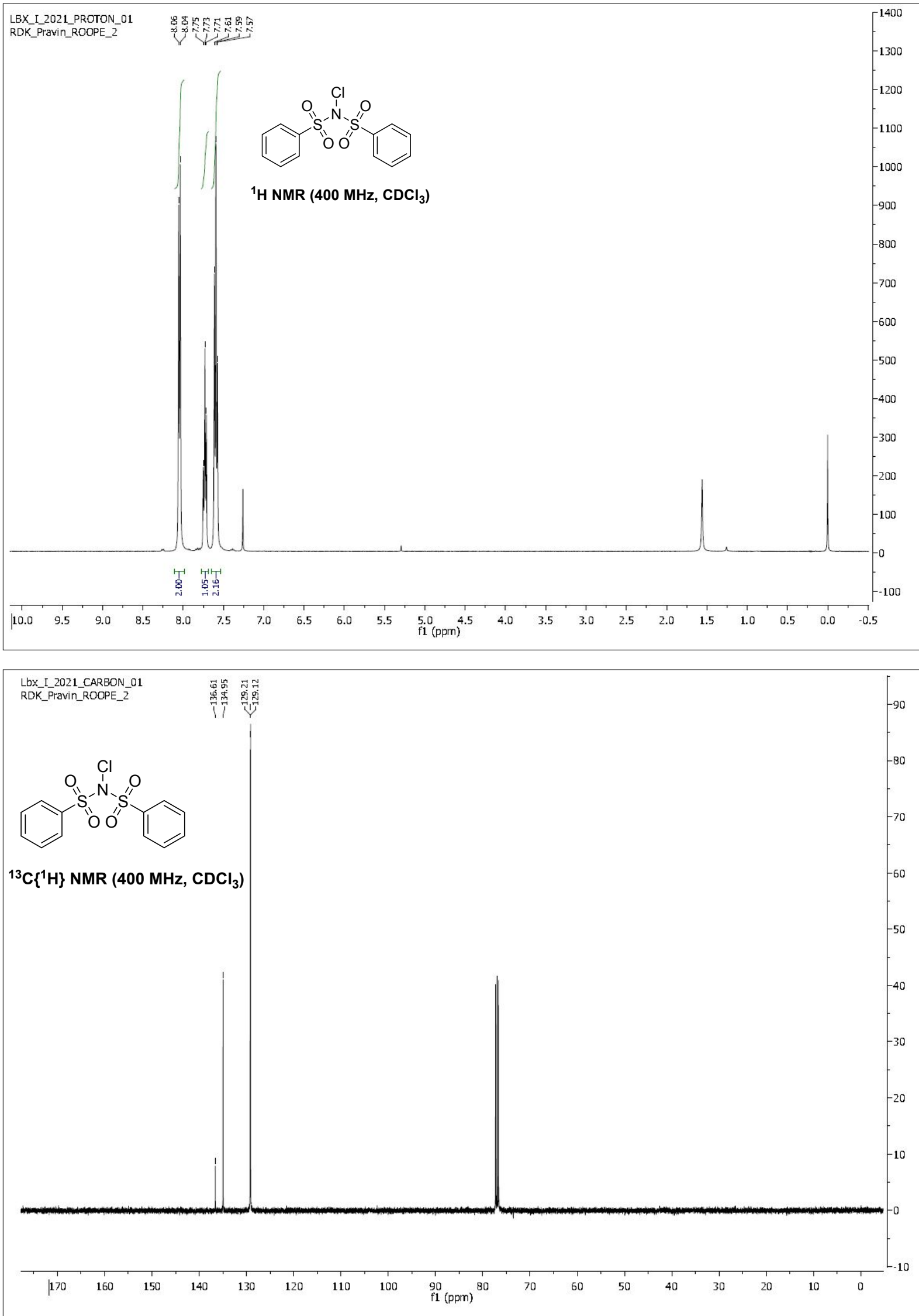